\title{
Roboterlösung für komplexe Bauteilgeometrien
}

\author{
Zur Reinigung sehr komplexer Bauteilgeometrien entschied sich ein OEM-Zulieferer für eine neue \\ Roboterlösung. Der robotergestützte Reinigungs- und Hochdruckprozess bringt eine hohe Flexibilität
}

beim Prozessablauf und verbesserte Reinigungsergebnisse.

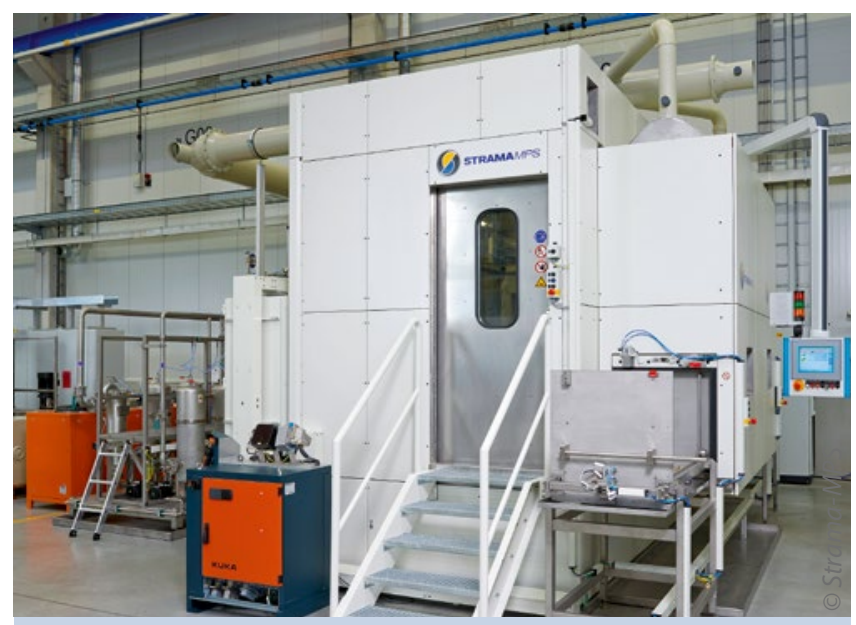

Ein flexibles Reinigungskonzept aus modularer Anlage und Roboterzelle integriert Reinigungsaufgaben mit wässrigen Lösungen in den Gesamtprozess

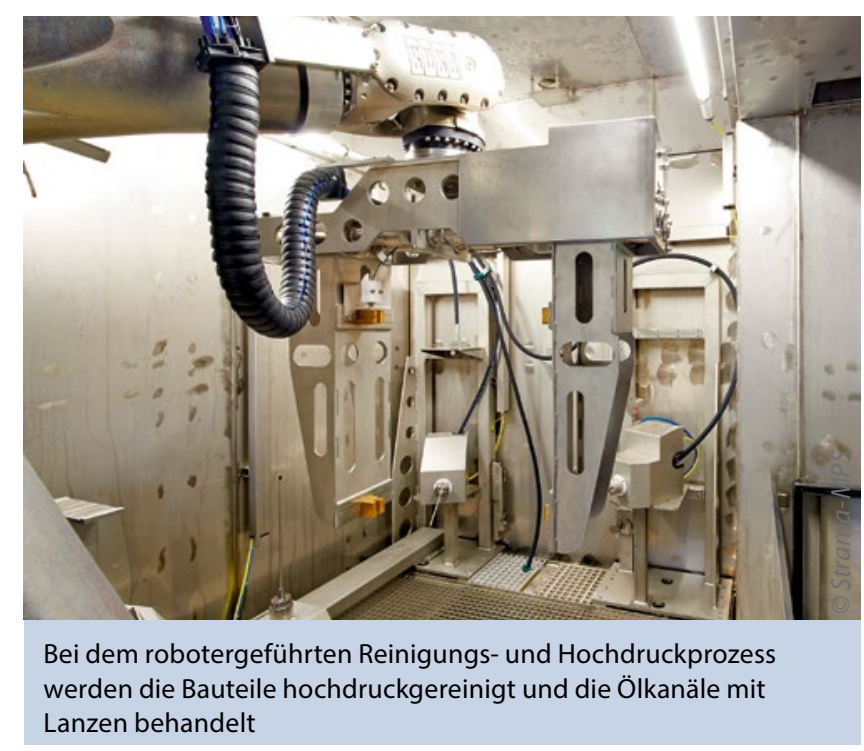

werden die Bauteile hochdruckgereinigt und die Ölkanäle mit Lanzen behandelt
$B_{k}^{2}$ auteilgeometrien werden immer komplexer und gleichzeitig ist die Qualität und Funktionsfähigkeit der Produkte in hohem Maße von der Reinheit der Bauteile abhängig. Und zu allem Überfluss drängt die Taktzeit. Die Fertigung muss deshalb zügig und flexibel auf Bauteilveränderungen reagieren können, wie auch bei einem OEMZulieferer, der auf flexible und effiziente Reinigungsprozesse angewiesen ist. 2014 lieferte Strama-MPS eine flexible Roboterlösung für sehr komplexe Bauteilgeometrien an den Zulieferer eines OEM-Premiumherstellers. Das Standard-Reinigungskonzept aus modularer Anlage (Promoclean) und Roboterzelle (Roboclean) integriert Reinigungsaufgaben mit wässrigen Lösungen in den Gesamtprozess. Der zu reinigende Motorblock des OEM-Zulieferers hat einen Durchmesser von circa $45 \mathrm{~cm}$ und eine Höhe von etwa $56 \mathrm{~cm}$ bei einem Ge- wicht von circa $50 \mathrm{~kg}$. Bei dem robotergeführten Reinigungs- und Hochdruckprozess werden am Bauteil überschüssige Oberflächenbeschichtungen mit 600 bar hochdruckgereinigt sowie dessen Ölkanäle mit langen, dünnen Lanzen behandelt. Zum Einsatz kommen hierzu rotierende und feststehende Düsen, wobei der Roboter das Bauteil an den Düsen positioniert und entsprechende Winkelstellungen anfährt. Somit werden stark verschleißfähige, spanabhebende Werkzeuge überflüssig.

\section{Schnelle Anpassung im}

Prozessablauf

Der Einsatz des Roboters lässt zudem zu, dass der Ablauf der Bauteilreinigung flexibel abgeändert werden kann. „Durch die Flexibilität des Roboters konnten die Düsenstellungen immer weiter optimiert werden, sodass die aktuellen Ergebnisse bei $100 \%$ liegen. Dies war mit den bis- herigen Anlagen nicht möglich", so der Leiter der Qualitätssicherung des OEM. Weitere Vorteile liegen in einer platzsparenden Bauweise und der flexiblen Beladung über ein Schubladensystem für maximale Auslastung der Anlage. Eine mehrstufige Filtration schafft eine längere Bäderstandzeit und schont die Anlagenkomponenten. Roboterlösungen stehen immer mehr im Fokus, um bestehende Anlagen und Konzepte abzulösen. Ein wesentlicher Vorteil liegt hierbei in der Flexibilität, um auf Bauteiländerungen schnell und gezielt reagieren $\mathrm{zu}$ können. Immer häufiger kommt es vor, dass serienreife Bauteile erst zur Endabnahme oder unmittelbar zum Produktionsstart zur Verfügung stehen und somit kurzfristige Modifikationen erforderlich sind.

\section{Kontakt:}

Strama-MPS Maschinenbau GmbH \& Co. KG, Straubing Tel. 09421739 146, www.strama-mps.de 